\title{
DIRECT COMPARISON OF THE EFFECTS OF ANTI-TNF BIOLOGICAL AGENTS IN PATIENTS WITH ANKYLOSING SPONDYLITIS
}

\author{
Essafi F, Saidane O, Mahmoud I, Ben Tekaya A, Tekaya R, Abdelmoula L \\ Department of Rheumatology, Charles Nicolle hospital
}

\section{Objectives : The aim of the present study was to compare} the efficacy of three anti-TNF agents (adalimumab, infliximab and etanercept ) in patients with ankylosing spondylitis (AS) at 24 weeks .

\section{Methods : We achieved a retrospective descriptive and} comparative monocentric study, on 23 patients, with AS (according to Amor criteria, ASAS 2009) who were handled during 12 years (2004-2015). The patients were treated with at least one anti-TNF, during at least 6 months. Disease activity was assessed by the BASDAI, ASDAS, ESR and CRP. To compare mean differences between time points (week 0 versus week 24), a Wilcoxon test was applied. To compare efficacy between the 3 anti-TNF, a Mann-Whitney test was applied.

\section{Results:}

\begin{tabular}{|l|l|}
\hline Patients & $\mathbf{2 3}$ \\
\hline Mean age (years) & $40,7 \pm 9,6$ \\
\hline Median age at disease onset (years) & $28,52 \pm 11,36$ \\
\hline Mean disease duration (years) & $9,6( \pm 7,17)$ \\
\hline
\end{tabular}

Table 1 :Baseline characteristics of patients starting TNF inhibitor

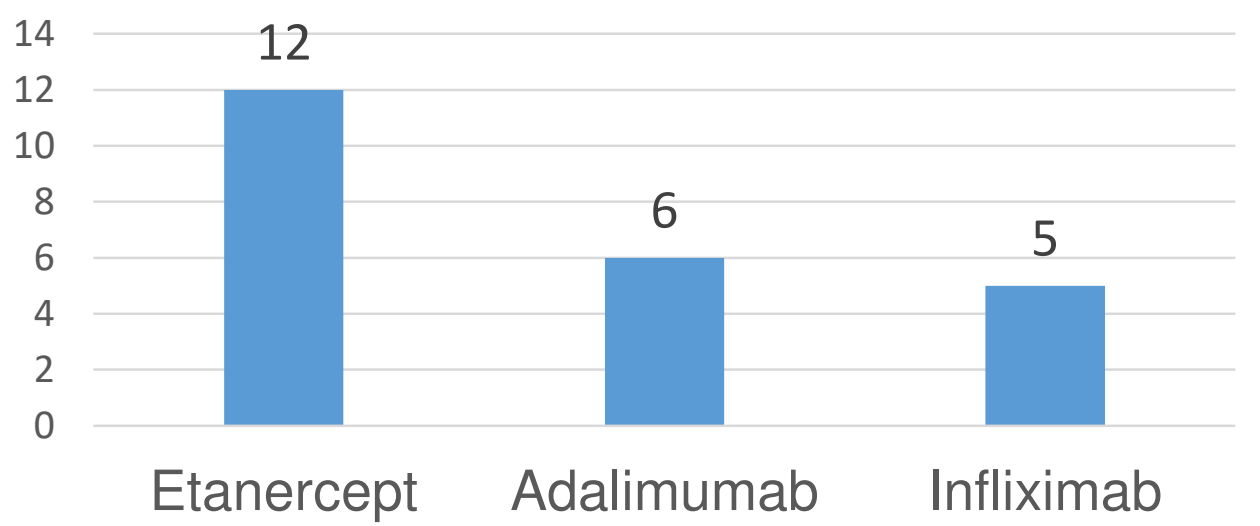

Figure 1: Anti-TNF alpha

\begin{tabular}{|llll|} 
& Week $\mathbf{0}$ & Week 24 & p \\
\hline BASDAl & $6,13 \pm 2,2$ & $2.36 \pm 2,2$ & $<0,0001$ \\
\hline ASDAS CRP & $4,03 \pm 0,97$ & $2,06 \pm 1,18$ & $<0,0001$ \\
\hline CRP $(\mathbf{m g} / \mathbf{l})$ & $29,77 \pm 24,14$ & $9,1 \pm 10,09$ & 0,001 \\
\hline ESR $(\mathbf{m m})$ & $53,5 \pm 34,8$ & $23,15 \pm 15,36$ & 0,002 \\
\hline
\end{tabular}

Table 2: Summary of median change from baseline to week 24 in clinical outcomes

Seventy percent of the patients have reached BASDAI 50 response at 6 months.

At week 24, patients on ETN achieved more frequently a significant reduction of ASDAS (-2,5 vs. $-1,17 ; p<0.04)$ and ESR $(-44,5$ vs. $-13,3 ; p=0,01)$ than IFX.

The "Face to Face" comparison ADA vs IFX and ADA vs ETN had shown no significant efficacy differences.

Discussion: According to the DANBIO registry, $63 \%$ of patients achieved a clinical response (BASDAI 50) at least once during the first 6 months [1]. Improvement in both ESR [mean improvement $27.3 \mathrm{~mm} / \mathrm{h}(95 \% \mathrm{Cl} 23.4,31.3)$ ] and CRP level [mean improvement $25.3 \mathrm{mg} / \mathrm{l}(95 \% \mathrm{Cl} 18.2,32.5)$ ] was also observed at 6 months [2]. The Finnish study among 543 patients with AS had shown no significant efficacy differences [3]. However, Giardina et al [4] compared ETN and IFX in 50 patients with AS. At week 12 more IFX than ETN treated patients achieved a significantly reduction of BASDAI (4.8 vs. $5.9 ; p<0.005$ and 3.5 vs. $5.6 ; p<0.005)$.

Conclusion: Our results showed a BASDAI 50 response in 70 $\%$ of patients. The comparison between the three biologics was consistent with a better efficacy of the ETN.

1] Glintborg B, Ostergaard M, Krogh NS, Dreyer L, Kristensen HL, Hetland ML. Predictors of treatment response and drug continuation in 842 patients with ankylosing spondylitis treated with anti-tumour necrosis factor: results from 8 years' surveillance in the Danish nationwide DANBIO registry. Ann Rheum Dis. 2010;69(11):2002-8.

[2] Lord PAC, Farragher TM, Lunt M, Watson KD, Symmons DPM, Hyrich KL. Predictors of response to anti-TNF therapy in ankylosing spondylitis: results from the British Society for Rheumatology Biologics Register. Rheumatology. 2010;49(3):563-70. [3]-Heinonen AV, Aaltonen KJ, Joensuu JT, Lähteenmäki JP, Pertovaara MI, Romu MK, et al. Effectiveness and drug survival of TNF inhibitors in the treatment of ankylosing spondylitis: a prospective cohort study. J Rheumatol. 2015;42(12):2339-46.

[4 ]Giardina AR, Ferrante A, Ciccia F, Impastato R, Miceli MC, Principato A, et al. A 2-year comparative open label randomized study of efficacy and safety of etanercept and infliximab in patients with ankylosing spondylitis. Rheumatol Int. 2010;30(11):1437-40. 